\title{
O gênero Siphanthera Pohl ex DC. (Melastomataceae) no estado de Minas Gerais
}

\author{
ROSANA ROMERO 1
}

(recebido em 20/12/95; aceito em 18/03/97)

\begin{abstract}
The genus Siphanthera Pohl ex DC. (Melastomataceae) in Minas Gerais state). The genus Siphanthera is represented in Brazil for thirteen species, occuring in highlands ("campos rupestres") and "campo úmido" associated with savannas ("cerrados"). Six species occur in the state of Minas Gerais: S. arenaria (DC.) Cogn., S. cordata Pohl ex DC., S. dawsonii Wurdack, S. foliosa (Naudin) Wurdack, S. gracillima (Naudin) Wurdack and S. paludosa (DC.) Cogn. The development of this investigation was based on observations of materials deposited in several herbaria and on observations in the field. A new record for Minas Gerais is presented, S. dawsonii, and two new citations in the literature, S. gracillima and S. foliosa. Key to the species, descriptions, illustrations, distribution and discussion of their taxonomic problems are given.

RESUMO - (O gênero Siphanthera Pohl ex DC. (Melastomataceae) no estado de Minas Gerais). O gênero Siphanthera está representado no Brasil por treze espécies, que ocorrem nos campos rupestres e nas áreas de campo úmido associadas aos cerrados. Em Minas Gerais ocorrem seis espécies: S. arenaria (DC.) Cogn., S. cordata Pohl ex DC., S. dawsonii Wurdack, $S$. foliosa (Naudin) Wurdack, S. gracillima (Naudin) Wurdack e S. paludosa (DC.) Cogn. A elaboração do presente trabalho foi baseada no estudo de exsicatas depositadas em vários herbários e em observações de campo. É acrescentado um novo registro para Minas Gerais, S. dawsonii, e duas novas citações na literatura, S. gracillima e S. foliosa. São apresentadas chave para as espécies, descrições, ilustrações, distribuição geográfica e discussão de seus problemas taxonômicos.
\end{abstract}

Key words - Siphanthera, Melastomataceae, Minas Gerais

\section{Introdução}

A família Melastomataceae constitui-se de cerca de 166 gêneros e 4200 espécies. Embora a família apresente uma distribuição pantropical, existe uma concentração de espécies no Novo Mundo, onde há aproximadamente 2950 espécies (Renner 1993).

O gênero neotropical sul-americano Siphanthera Pohl ex DC., que atualmente inclui Meisneria DC., Tulasnea Naudin e Farringtonia Gleason, apresenta 16 espécies com ocorrência na Colômbia, Venezuela, Brasil e Bolívia (Renner 1993). No Brasil há cerca de 13 espécies que ocorrem, principalmente, nos campos rupestres de Minas Gerais e Goiás e em áreas de campo úmido associadas aos cerrados de Minas Gerais, Mato Grosso e Rondônia.

As plantas são pequenas ervas, anuais ou perenes com flores fugazes e inconspícuas, caracteres que combinados resultam em poucas coletas e dificuldades de identificação (Wurdack 1963). Provavelmente isso explique, em parte, a falta de coletas de algumas espécies do gênero no estado de Minas Gerais.

O presente trabalho teve como objetivo reunir informações acerca do gênero e suas espécies no estado de Minas Gerais, discutir seus problemas

1. Departamento de Biociências, Universidade Federal de Uberlândia. Caixa Postal 593, 38400-902 Uberlândia, MG, Brasil. taxonômicos, fornecer descrições e ilustrações possibilitando um melhor conhecimento destas espécies.

\section{Material e métodos}

A elaboração deste trabalho foi baseada no estudo de exsicatas provenientes dos seguintes herbários: BHCB, HUFU, R, RB, SP, SPF, UEC e US. Também foram realizadas observações e coletas regulares de exemplares de Siphanthera nos anos de 1993, 1994 e primeiro semestre de 1995 nas formações de campo úmido e veredas da Reserva do Clube Caça e Pesca Itororó e da Estação Ecológica do Panga, ambas localizadas no município de Uberlândia, e do Parque Nacional da Serra da Canastra, localizado nos municípios de São Roque de Minas, Sacramento e Delfinópolis. Os exemplares coletados nestas áreas estão incorporados no Herbarium Uberlandense (HUFU). Dados de floração e frutificação de quatro espécies foram anotados no campo e partes representativas de flores e/ou frutos foram fixadas em álcool $70 \%$ para análise e ilustração dos detalhes florais. As observações de $S$. arenaria e $S$. paludosa foram feitas somente com base em exsicatas. As ilustrações foram feitas em câmara-clara acoplada a um estereoscópio Zeiss.

Para a identificação das espécies utilizou-se a chave analítica da família Melastomataceae de Cogniaux (1883) e os trabalhos de Wurdack $(1959,1963)$.

\section{Resultados e Discussão}

Siphanthera Pohl ex DC.; Prodr. 3:114. 1828.

Meisneria DC., Prod. 3:114. 1828.

Tulasnea Naudin, Ann. Sci. Nat. ser 3 Bot. 2:142. 1844.

Farringtonia Gleason, Fieldiana Bot. 28:426. 1952. 
Ervas ou subarbustos pouco ramificados ou não. Ramos pilosos, hirsutos ou glandulosos. Folhas sésseis ou curtamente pecioladas, inteiras, serreadas ou crenuladas, com 1 a 5 nervuras acródromas basais. Flores em panículas, em glomérulos ou isoladas, axilares e/ou terminais, sésseis ou pediceladas, 4meras. Brácteas semelhantes às folhas, persistentes, externamente com tricomas glandulares e internamente glabras. Hipanto glanduloso-piloso; lacínias do cálice triangulares, persistentes, ápice agudo, externamente indumento igual ao do hipanto, internamente glabros. Pétalas brancas, róseas ou purpúreas, obovadas, subarredondadas ou arredondadas, levemente unguiculadas, ápice arredondado. Estames 8, desiguais; 4 férteis opostos às sépalas e 4 rudimentares opostos às pétalas, ou apenas 4 férteis; anteras ovóides, ovóide-oblongas ou oblongas, ápice rostrado ou truncado; conectivo curtamente prolongado e anteriormente bilobado; filetes filiformes, glabros. Ovário livre, ovóide, glabro, 2locular; estilete reto, filiforme, glabro; estigma punctiforme ou truncado. Fruto cápsula subglobosa, 2-valvada, deiscente do ápice para a base, envolta pelo hipanto prolongado. Sementes pequenas, ovóides e reniformes, levemente reticuladas, aréolas alargadas.

Até o momento eram conhecidas para o estado de Minas Gerais sete espécies de Siphanthera: $S$. arenaria, S. cordata, S. discolor, S. miqueliana, $S$. paludosa, $S$. robusta e $S$. villosa. Mas de acordo com O. Robinson \& F. Almeda (comunicação pessoal), que estão elaborando a revisão deste gênero, no estado ocorrem apenas cinco espécies, sendo as demais sinônimos que serão propostos por eles em sua monografia. No presente trabalho é acrescentado um novo registro para o estado, $S$. dawsonii, e duas novas citações na literatura, S. gracillima e $S$. foliosa (figura 1).

Chave para as espécies de Siphanthera:

1. Anteras com ápice rostrado

2. Anteras ovóides

Siphanthera arenaria

2. Anteras oblongas

3. Quatro estames, inflorescências em glomérulos Siphanthera cordata

3. Oito estames, inflorescências em panículas Siphanthera paludosa 1.Anteras com ápice truncado, não rostrado

4. Folhas lineares Siphanthera foliosa

4. Folhas ovais

5. Pétalas róseas, presença de estaminódios Siphanthera gracillima

5. Pétalas brancas, ausência de estaminódios Siphanthera dawsonii

Siphanthera arenaria (DC.) Cogn., Fl. Bras. 14 (3): 193. 1883.

Erva de 10-30 cm alt. Ramos obscuramente quadrangulares, densamente revestidos de tricomas glandulares. Folhas sésseis; limbo oval-oblongo, 1,57 x 0,8-3 mm, base arredondada, às vezes cordada, ápice agudo, margem inteira, ambas as faces pilosas e entremeadas de tricomas glandulares, com 3 nervuras acródromas basais, raramente com 5 nervuras. Flores axilares ou terminais; pedicelos ca. $2 \mathrm{~mm}$ compr. Brácteas ca. 1,8 x 0,5 mm. Hipanto campanulado, ca. 1,5 x $2 \mathrm{~mm}$, densamente com tricomas glandulares. Lacínias do cálice ca. 1,6 x 1 $\mathrm{mm}$ na base. Pétalas róseas ou arroxeadas, obovadas e levemente unguiculadas, 2,5 x 2,3 mm. Estames 4, férteis, antesépalos; filetes 1,5 mm compr.; anteras amarelas, ovóides, ca. $1 \mathrm{~mm}$ compr., curtamente rostradas; rostro ca. $0,3 \mathrm{~mm}$ compr.; conectivo prolongado $0,1 \mathrm{~mm}$ além dos lóculos da antera. Estilete ca. 3,5 $\mathrm{mm}$ compr.; estigma punctiforme (figuras 2-4).

Material examinado - Minas Gerais - Caraça, caminho para a Gruta, M.B. Horta et al. 42, 24.V.1987 (BHCB); Congonhas do Norte, Retiro Barbado, M.C.E. Amaral, A. Furlan \& N. Hensold 8417, 22.IV.1982 (US); Couto Magalhães, Chapada do Couto, E. Varanda et al. 4646, 17. VII. 1984 (SPF); Diamantina, N.L. Menezes et al. 80, 18.VII.1980 (UEC), id., estrada Conselheiro da 


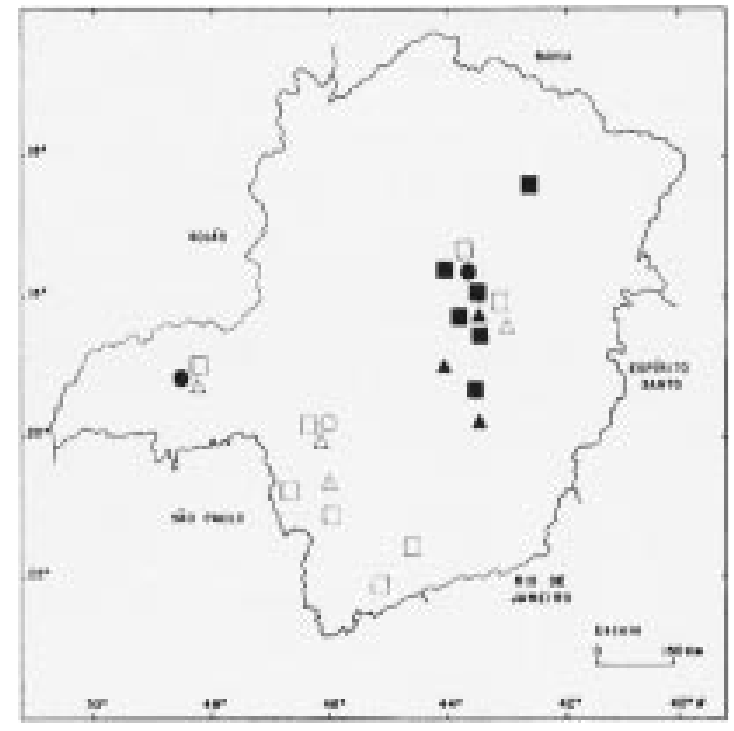

Figura 1. Distribuição das espécies de Siphanthera em Minas Gerais: $S$. arenaria $(\square), S$. cordata $(\square), S$. dawsonii $(\bigcirc)$, S. foliosa $(\bigcirc), S$. gracilliama $(\triangle)$ e $S$. paludosa $(\mathbf{\Delta})$.

Mata-Diamantina, N.S. Chukr et al. 9513,23.II. 1986 (SPF); id., estrada Diamantina-Biribiri, Splett 909, 13.III.1995 (US); Gouveia, 66 km da estrada Curvelo-Diamantina, A. Furlan et al 3207, 09.IV. 1982 (SPF); Grão-Mogol, direção nordeste da cidade, N. Hensold et al. 3446, 22.V.1982 (UEC); id., vale do Rio ltabiruçu, R. Simão-Bianchini et al. 12912, 14.VI.1990 (US); Jaboticatubas, km 132 ao longo da rodovia Lagoa Santa-Conceição do Mato Dentro-Diamantina, A.B. Joly et al. 216, 07.VI. 1970 (UEC); id., km 142 ao longo da rodovia Lagoa Santa-Conceição do Mato DentroDiamantina, J. Semir \& M. Sazima 1999, 30.IV.1972 (UEC); id., A.B. Joly et al. 2102, 27.V. 1972 (UEC); id., km 140 ao longo da rodovia Lagoa Santa-Conceição do Mato Dentro-Diamantina, A.B. Joly et al. 1320, 06.III.1972 (UEC); Joaquim Felício, Serra do Cabral, R. Mello-Silva et al. 8118, 01.IX.1985 (SPF, US); Santana do Pirapama, Fazenda Inhame, J.R. Pirani et al. 8093; s/d (US); Santana do Riacho, P.M. Andrade \& M.A. Lopes s/n, 15.IV.1985 (BHCB); id., estrada Lagoa Santa-Conceição do Mato Dentro, A.M. Giullietti 7321, 30.VI.1981 (UEC); Serra do Cipó, Retiro do Alto do Palácio, 25 km NE de Cardeal Mota, M.M. Arbo et al. 4253, 16.V.1990 (SPF, US); Serra do Cipó, J.R. Pirani et al. 12045, 26.III.1991 (SPF).
Siphanthera arenaria é encontrada somente no estado de Minas Gerais, ocorrendo exclusivamente nas formações de campo limpo arenoso e campo úmido da Serra do Espinhaço. Esta espécie floresce e frutifica nos meses de fevereiro - julho.

Siphanthera cordata Pohl ex DC., Prodr. 3:121. 1828. Siphanthera gracilis Miq., Linnaea 22: 537. 1849.

Erva de 30-40 cm alt. Ramos obscuramente quadrangulares, densamente revestidos de tricomas glandulares. Folhas sésseis ou pecíolos de até $3 \mathrm{~mm}$ compr.; limbo oval, 4-10 x 4-8 mm, base cordada, ápice agudo, margem crenulada, ambas as faces moderada a densamente revestidas de tricomas glandulares, com 3-5 nervuras acródromas basais. Inflorescências em glomérulos axilares e terminais, multifloras. Brácteas ca. 4 x 2-3 mm. Flores quase sésseis, pedicelos ca. 0,3 mm compr. Hipanto oblongo, ca. 3 x 1,5 mm, com tricomas glandulares esparsos. Lacínias do cálice ca. 3 x 1,5 mm na base. Pétalas róseas ou arroxeadas, obovadas e levemente unguiculadas, 3-4,5 x 3-4 mm. Estames 4, férteis; filetes 4-4,5 mm compr.; anteras roxas, oblongas, ca. $3 \mathrm{~mm}$ compr., longamente rostradas; rostro ca. $1 \mathrm{~mm}$ compr.; conectivo prolongado 0,4-0,6 mm além dos lóculos da antera. Estilete ca. $10 \mathrm{~mm}$ compr.; estigma punctiforme (figuras 5-8).

Material examinado - Minas Gerais - Alpinópolis, Furnas, Fazenda Salto, F.R. Martins 168, 28.VII.1976 (UEC); Curvelo, F. de Barros 146, 06.IV.1980 (UEC); Datas, Morro do Coco, J.R. Pirani \& R. Mello-Silva 12175, 21.III.1989 (SPF, US); Diamantina, estrada para Guinda, Rio das Pedras, N.L. Menezes \& M. Meguro 9797, 04. IV. 1986 (SPF, US); id., 5 km W de Diamantina, caminho p/ Gouveia, M.M. Arbo et al. 5212. 16.II.1991 (US); Gouveia, J. Prado et al. 10447, 14.IV.1987 (US); São Roque de Minas, Parque Nacional da Serra da Canastra, J.N. Nakajima et al. 319, 19.IV. 1994 (HUFU); id., R. Romero et al. 1863, 16.III.1995 (HUFU); id., R. Romero et al. 2018, 19.III.1995 (HUFU); id., R. Romero et al. 2117, 09.V.1995 (HUFU); id., R. Romero et al. 2271, 14.V.1995 (HUFU); id., J.N. Nakajima \& R. Romero 1790, 26.V. 1996 (HUFU); São Sebastião do Paraíso, J. Vidal s/n, 1945 (R108234); Serra do Cabral, $85 \mathrm{~km}$ de Corinto, estrada para Joaquim Felício, P.E. Gibbs et al. 5013, 13.V.1977 (UEC); 
Serra de Carrancas, A. Silveira s/n, 1897 (R 136698); Thermópolis, Chapada do Jacuhy, J. Vidal 877, IV/1945 (R); Uberlândia, Estação Ecológica do Panga, G.M. Araújo et al. 38, 10.IV.1992 (HUFU); id., G.M. Araújo 119, 15.V.1992 (HUFU); id., J.N. Nakajima \& R. Romero 103, 01.V.1993 (HUFU); Reserva Ecológica do Clube Caça e Pesca Itororó, R. Romero et al. 1000, 17.V.1994 (HUFU); id., R. Romero 2103, 05.V.1995 (HUFU); Unaí, Fazenda São Miguel, B.A.S. Pereira \& D. Alvarenga 2080, $23 . I V .1992$ (US); B.A.S. Pereira \& D. Alvarenga 2080, Unaí, Fazenda São Miguel (Grupo Votorantin), 23.IV.1992 (US).

Miquel (1849) descreveu Siphanthera gracilis baseado em um material coletado por Regnell em Caldas, MG. Na revisão que fez para Melastomataceae, Cogniaux (1883) examinando os exemplares coletados por Regnell, classificados como $S$. gracilis, constatou a presença de dois espécimes diferentes com um mesmo número. Cogniaux (1883), então, descreveu como uma nova espécie parte deste material dando o nome de Siphanthera miqueliana em homenagem a Miquel. A outra parte do material, ele concluiu que era Siphanthera cordata, espécie já descrita por De Candolle (1828). Desta maneira, Cogniaux (1883) deixou Siphanthera gracilis como sinonímia de Siphanthera cordata.

Na chave elaborada por Cogniaux (1883), os caracteres que separam Siphanthera cordata de Siphanthera miqueliana são muito tênues, ou seja, folhas sésseis para a primeira e folhas curtamente pecioladas (com ca. de $2 \mathrm{~mm}$ ) para a segunda. A maioria dos espécimes de $S$. cordata estudados apresenta folhas sésseis e, mais raramente, folhas curtamente pecioladas, com pecíolos de até $3 \mathrm{~mm}$ de comprimento.

Ainda, segundo Cogniaux (1883), em S. cordata as inflorescências apresentam flores dispostas em glomérulos no ápice dos ramos imitando espigas interrompidas. Este tipo de inflorescência foi freqüentemente observado, porém, algumas vezes, também foram observados ramos com flores fasciculadas terminais, sendo esta uma característica de $S$. miqueliana, segundo a descrição de Cogniaux (1883).

Analisando as descrições das duas espécies, observa-se que os caracteres distintivos entre $S$. cordata e S. miqueliana são muito inconsistentes. E, embora os holotipos destas duas espécies não tenham sido analisados, ao que tudo indica $S$. miqueliana parece não ser diferente de $S$. cordata, mas sim uma variação desta última, e talvez uma sinonimização deva ser feita futuramente.

No município de Uberlândia Siphanthera cordata ocorre na transição campo úmido-campo sujo, onde o solo é bastante arenoso e hidromórfico, enquanto que no Parque Nacional da Serra da Canastra foi encontrada tanto em campo úmido, com solo bastante encharcado, como em campo limpo, em meio a populações de Cyperaceae e Poaceae.

Esta espécie floresce em março, abril e maio, apresentando frutos, principalmente, no mês de maio. S. cordata ocorre nos estados de São Paulo, Minas Gerais, Goiás e Mato Grosso.

Siphanthera dawsonii Wurdack, County Mus. Contrib. Sci. 28: 8. 1959.

Erva de ca. $10 \mathrm{~cm}$ alt. Ramos quadrangulares, moderadamente híspido-glandulosos. Folhas em pecíolos de 1-3 mm compr., limbo oval, 5-7,5 x 2,5-6 $\mathrm{mm}$, base arredondada, ápice obtuso, margem crenulada, ambas as faces com tricomas glandulares esparsos, com 3 nervuras acródromas basais, às vezes, apenas uma nervura. Flores poucas, agregadas no ápice dos ramos. Brácteas 3,5-4,5 mm compr. Flores quase sésseis, pedicelos ca. $0,3 \mathrm{~mm}$ compr. Hipanto oblongo, ca. 2,5 x 1,5 mm, com tricomas glandulares esparsos. Lacínias do cálice ca. 2 x 1 $\mathrm{mm}$ na base. Pétalas brancas, obovadas e levemente unguiculadas, $2 \times 1,5 \mathrm{~mm}$. Estames 4, opostos às sépalas; filetes ca. $2,2 \mathrm{~mm}$ compr.; anteras roxas, ovóides, 0,6 mm compr., não rostradas, ápice truncado e o poro inclinado dorsalmente; conectivo prolongado ca. 0,6 $\mathrm{mm}$ além dos lóculos da antera. Estilete levemente espessado em direção ao ápice, ca. 3,5 mm compr.; estigma truncado (figuras 9-14). Material examinado - Minas Gerais - São Roque de Minas, Parque Nacional da Serra da Canastra, J.N. Nakajima \& R. Romero 1043, 12.V. 1995 (HUFU)

S. dawsonii assemelha-se muito a S. gracillima no aspecto vegetativo diferindo desta, principalmente, por apresentar as anteras com um diminuto poro inclinado dorsalmente, pétalas alvas e ausência de estaminódios, enquanto que em $S$. gracillima, as anteras apresentam um amplo poro 


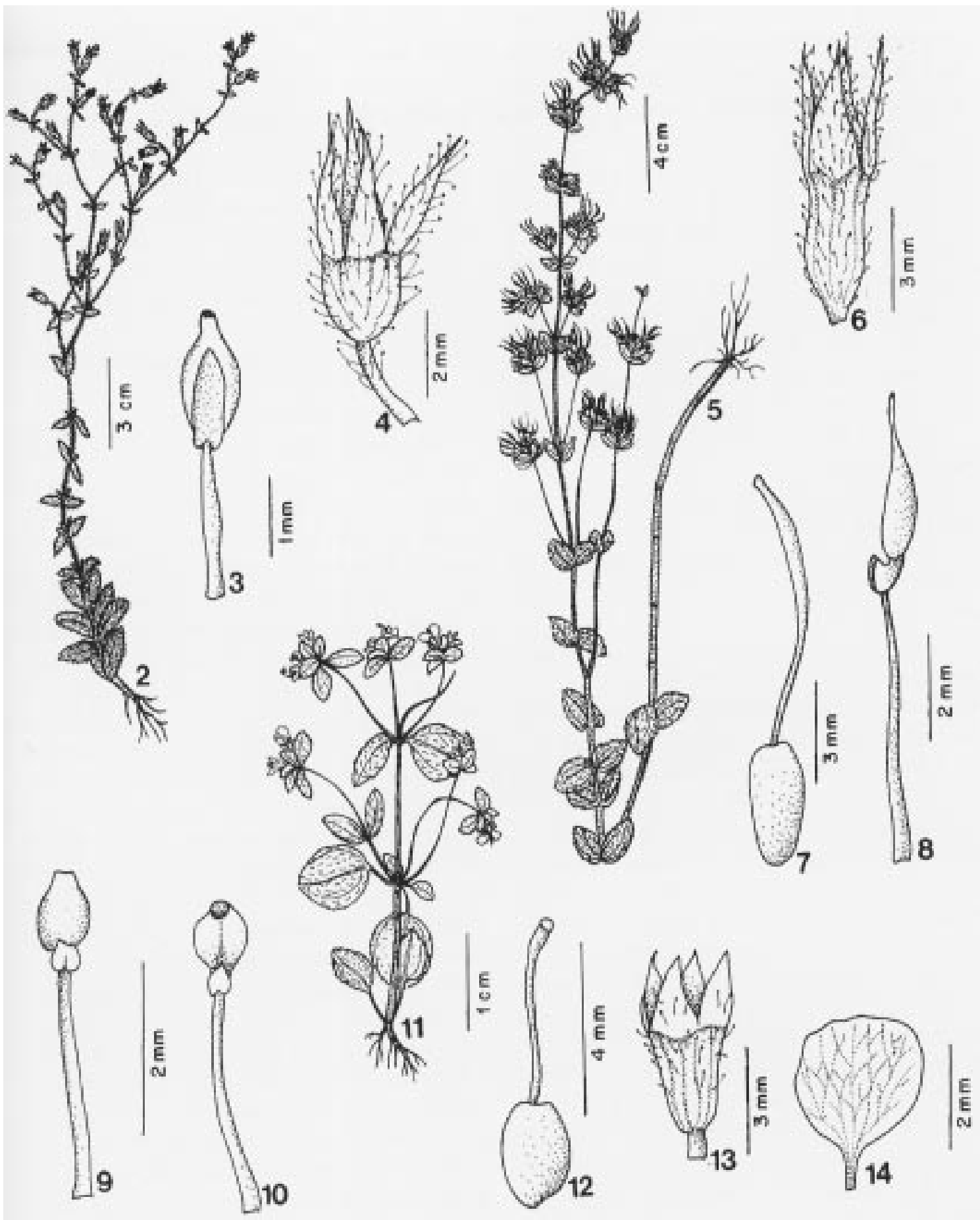

Figuras 2-4. Siphantera arenaria (DC.) Cogn.. 2. Ramo; 3. Estame; 4. Hipanto (A.B. Joly 2102). 5-8. Siphanthera cordata Pohl. ex DC.. 5. Ramo; 6. Hipanto; 7. Gineceu; 8 Estame (R. Romero et al. 1000). 9-14. Siphanthera dawsonii Wurdack. 9. Vista posterior do estame; 10. Vista frontal do estame; 11. Ramo; 12. Gineceu; 13. Hipanto; 14. Pétala (J.N. Nakajima \& R. Romero 1043). 
inclinado ventralmente, pétalas róseas e estaminódios inconspícuos opostos às pétalas.

S. dawsonii foi encontrada somente no Parque Nacional da Serra da Canastra, em afloramentos rochosos, entre fendas de rochas onde existe uma certa umidade. Esta espécie foi vista florescendo e frutificando no mês de maio, sendo que em julho a população já tinha desaparecido. Segundo O. Robinson (comunicação pessoal), esta espécie foi encontrada no Brasil nos estados de Goiás, Mato Grosso, Pará e na Venezuela, no estado de Bolivar, sendo possível sua ocorrência em outras localidades. S. dawsonii é citada pela primeira vez para o estado de Minas Gerais.

Siphanthera foliosa (Naudin) Wurdack, Mem. N.Y. Bot. Gard. 10(1):97. 1958.

Tulasnea foliosa Naudin. Ann. Sci. Nat. ser 3 Bot. 2:143. 1844.

Potheranthera foliosa (Naudin) Cogn., DC. Monog. Phan. 7:121. 1891.

Potheranthera minor Gleason, Bull. Torrey Club. 52: 339. 1925.

Erva decumbente de $20-40 \mathrm{~cm}$ alt. Ramos obscuramente quadrangulares, jovens moderadamente piloso-glandulares, depois glabros, nós finosetulosos. Folhas sésseis; limbo linear, 7-12 x 1-2,3 $\mathrm{mm}$, ápice agudo, margem inteira e no ápice levemente denteada, glabras nas duas faces, com 1 nervura acródroma basal, às vezes com 3 nervuras. Inflorescências em panículas terminais, multifloras, densamente revestidas de tricomas glandulares. Brácteas 2,3-3,2 x 0,6-0,7 mm. Flores em pedicelos ca. 1,5-3 mm compr. Hipanto campanulado, 2-2,3 x 2,4-2,9 mm, moderadamente revestido de tricomas glandulares. Lacínias do cálice 3-3,5 x 1,6-1,8 mm na base. Pétalas róseas, obovadas, 3,5-4 x 3-3,5 mm de larg. Estames 8; 4 opostos às sépalas; filetes 1,6-2 mm compr.; anteras roxas, elipsóides 0,7$0,8 \mathrm{~mm}$ compr., não rostrada, ápice truncado com um amplo poro; conectivo prolongado 0,2-0,3 mm além dos lóculos da antera; 4 opostos às pétalas; filetes ca. 1,5 mm compr.; anteras 0,2-0,3 mm compr. Estilete 1,5-2,2 mm compr.; estigma truncado (figuras 15-19).

Material examinado - Minas Gerais - Buenópolis, Serra do Cabral, 10-15 km da cidade, R.M. Harley et al. 24960, 13.X.1988 (SPF, US); Uberlândia,
Reserva Ecológica do Clube Caça e Pesca ltororó, J.N. Nakajima et al. 115, 13.VIII.1993 (HUFU); id.. R. Romero et al. 1097, 03.VIII.1994 (HUFU).

Naudin (1844) estabeleceu o gênero Tulasnea com apenas duas espécies, Tulasnea foliosa e Tulasnea gracillima, ambas com ocorrência no estado de Goiás. Cogniaux (1883), na revisão que fez para a família Melastomataceae, manteve o gênero Tulasnea com as duas espécies propostas por Naudin (1844), mas em um outro estudo elaborado com a família, alguns anos mais tarde, Cogniaux (1891) transferiu as duas espécies de Tulasnea para o gênero Poteranthera Bongard., mantendo os epítetos propostos por Naudin (1844) e deixando, assim, Tulasnea foliosa e Tulasnea gracillima como sinonímias de Poteranthera foliosa e Poteranthera gracillima, respectivamente.

Wurdack $(1958,1959)$ depois de examinar o holotipo de Poteranthera foliosa (Naudin) Cogn. e de Poteranthera gracillima (Naudin) Cogn., concluiu que ambas parecem muito, no aspecto geral, com as espécies do gênero Siphanthera, e propôs, então, uma nova combinação binomial, Siphanthera foliosa (Naudin) Wurdack e Siphanthera gracillima (Naudin) Wurdack, nomes atualmente aceitos.

Uma pequena população de Siphanthera foliosa foi encontrada na Reserva Ecológica do Clube Caça e Pesca Itororó, município de Uberlândia, na formação de vereda, onde o solo apresenta-se bastante encharcado. É uma espécie bem característica apresentando tanto a parte vegetativa como as peças florais e os frutos em tons avermelhados. Esta espécie floresce, principalmente, nos meses de julho e agosto, apresentando frutos no mês de agosto. Além desta localidade, observou-se uma única coleta de $S$. foliosa na Serra do Cabral. A espécie é citada para os estados de Goiás (Cogniaux 1883) e Mato Grosso (Hoehne 1922). Segundo Wurdack (1973), S. foliosa ocorre também nas savanas baixas da Venezuela, estendendo-se desde a Colômbia até a região central do Brasil, nos estados de Goiás, Mato Grosso e em Rondônia, porém não sendo conhecida nas regiões intermediárias. Embora esta espécie já tenha sido coletada em Minas Gerais, ela está sendo citada pela primeira vez em literatura.

Siphanthera gracillima (Naudin) Wurdack, County Mus. Contrib. Sci. 28: 8. 1959. 
Tulasnea gracillima Naudin. Ann. Sci. Nat. ser 3 Bot. 2:143. 1844.

Potheranthera gracillima (Naudin) Cogn., DC. Monog. Phan. 7:121. 1891.

Erva de 7-15 cm alt. Ramos quadrangulares, moderadamente híspido-glandulosos. Folhas sésseis; limbo oval ou oval-oblongo, 6-11 x 4-7 mm, base arredondada, ápice obtuso, margem levemente denteada, face superior e inferior esparsamente híspido-glandulosa, com 3 nervuras acródromas basais. Brácteas 2,8-3,4 x 1-1,5 mm. Flores poucas, axilares ou terminais; pedicelos ca. $1 \mathrm{~mm}$ compr. Hipanto campanulado, ca. 1,8 x 1,5 mm, densamente híspido-glanduloso. Lacínias do cálice 1,5-2 x 1 $\mathrm{mm}$ na base. Pétalas róseas, obovadas, ca. 2,3 x 2,3 $\mathrm{mm}$. Estames 8; 4 férteis opostos às sépalas e 4 estéreis imperfeitos apostos às pétalas; filetes ca. 2,7 mm compr.; anteras roxas, ovóides, ca. 1,2 mm compr., não rostradas, ápice truncado com um amplo poro inclinado ventralmente; conectivo prolongado ca. 0,5 mm além dos lóculos da antera. Estilete levemente espessado em direção ao ápice; estigma truncado (figuras 20-24).

Material examinado - Minas Gerais - Curralinho, perto de Diamantina, Glaziou 19279, 14.IV.1892 (R); Diamantina, Schwacke 17855, 14.IV.1892 (RB); Delfinópolis, estrada da represa dos Peixotos, R. Romero \& J.N. Nakajima 3417 e 3418, 22.V.1996 (HUFU); Furnas, (Ribeirão das Pacas-Cascata), L. Emygdio 2289, 28.VII.1966 (R); estrada GuindaConselheiro da Mata, km 176, H.F. Leitão-Filho et al. 17405, 04.VI.1985 (UEC); Uberlândia, Reserva Ecológica do Clube Caça e Pesca Itororó, R.Romero et al. 999, 17.V.1994 (HUFU); id., R. Romero \& A.A. Arantes 1011, 24V. 1994 (HUFU); id., R. Romero 2104, 05.V.1995 (HUFU); id., R. Romero 2341. 31.V. 1995 (HUFU); Estação Ecológica do Panga, R. Romero et al. 997, 05.VI.1992 (HUFU); id., J.N. Nakajima \& R. Romero 102, 01.V.1993 (HUFU); São Roque de Minas, Parque Nacional da Serra da Canastra, R. Romero et al. 997, 21.IV. 1994 (HUFU); id., J.N. Nakajima et al. 1119, 15.V.1995 (HUFU).

Siphanthera gracillima, uma erva com $7-15 \mathrm{~cm}$ de comprimento, foi encontrada em áreas de campo úmido associadas a cerrados na Reserva Ecológica do Clube Caça e Pesca Itororó e na Estação Ecológica do Panga, município de Uberlândia, com poucos indivíduos, os quais ficam praticamente escondidos entre populações de Cyperaceae e Poaceae. Já no Parque Nacional da Serra da Canastra esta espécie ocorre em locais úmidos associados a afloramentos rochosos. O hábito diminuto e as flores muito delicadas e efêmeras de $S$. gracillima dificultam a localização de seus indivíduos, o que possivelmente explica a falta de coleções desta espécie nos herbários consultados. Isto pode ser exemplificado pelo fato de O. Robinson \& F. Almeda (comunicação pessoal), terem examinado apenas nove exsicatas desta espécie num total de 26 herbários consultados. Siphanthera gracillima floresce e frutifica, principalmente, nos meses de abril, maio e junho. Esta espécie ocorre nos estados de Goiás e Mato Grosso, sendo que no presente trabalho sua distribuição é ampliada também para o estado de Minas Gerais.

Siphanthera paludosa (DC.) Cogn., Fl. Bras. 14 (3): 191. 1883.

Erva de 30-40 cm alt. Ramos cilíndricos. adpresso-setosos e entremeados de tricomas glandulares. Folhas sésseis; limbo oval ou oval-oblongo, 8-15 x 5-8 mm, base arredondada, ápice agudo, margem inteira, face superior moderada a densamente vilosa, face inferior densamente vilosa, principalmente ao longo das nervuras, com 3-5 nervuras acródromas basais. Inflorescências em panículas terminais, multifloras, densamente revestida de tricomas glandulares. Brácteas ca. 1,5 x $0,5 \mathrm{~mm}$. Flores pediceladas, pedicelos $2 \mathrm{~mm}$ compr. Hipanto campanulado, ca. 2 x 1,8 mm, moderadamente com tricomas glandulares. Lacínias do cálice ca. 2,5 x $1 \mathrm{~mm}$ na base. Pétalas arroxeadas, obovadas e levemente unguiculadas, 4-5 x $4 \mathrm{~mm}$. Estames 8, férteis; filetes 1,6-2,6 mm compr.; anteras amarelas, oblongas, 1-2 mm compr., longamente rostradas; rostro $0.5-1 \mathrm{~mm}$ compr.; conectivo prolongado 0.1-0,3 $\mathrm{mm}$ além dos lóculos da antera. Estilete ca. $6 \mathrm{~mm}$ compr.; estigma punctiforme (figuras 25-28). Material examinado - Minas Gerais Datas, morro do Coco, próximo a Diamantina, R. Mello-Silva \& J.R. Pirani 12176, 21.III.1989 (SP, US); ca. $10 \mathrm{~km} \mathrm{SW}$ of Diamantina, W.R. Anderson, M. Stieber \& J.H. Kirkbride 35238, 03.II.1972 (US); Jaboticatubas, km 137 ao longo da rodovia Lagoa 


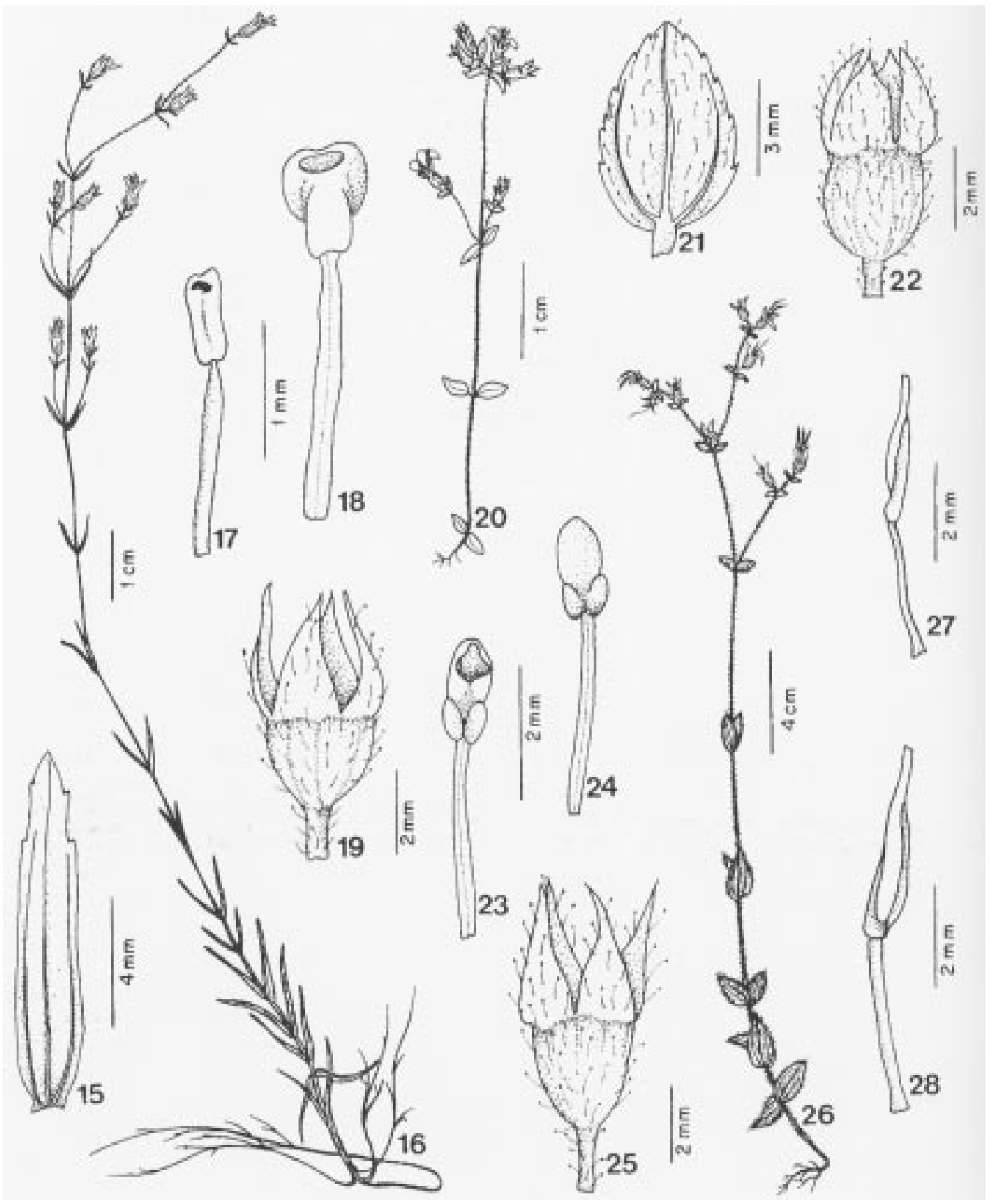

Figuras 15-19. Siphanthera foliosa (Naud.) Wurdack. 15. Face abaxial da folha; 16. Ramo; 17. Estame menor; 18. Estame maior; 19. Hipanto (R. Romero et al. 1097). 20-24. Siphanthera gracillima (Naud.) Wurdack. 20. Ramo; 21. Face abaxial da folha; 22. Hipanto; 23. Vista frontal do estame; 24. Vista posterior do estame (R. Romero et al. 999). 25-28. Siphanthera paludosa (DC.) Cogn. 25. Hipanto; 26. Ramo; 27. Estame menor; 28. Estame maior (J.R. Pirani et al. 8687). 
Santa-Conceição do Mato Dentro, J. Semir \& A.M. Joly 3759, 06.I.1973 (UEC); id., km 132, M. Sazima \& J. Semir 3899, 16-24.II.1973 (UEC); Santana do Pirapama, Fazenda Inhame, J.R. Pirani et al. 8186, 23.III.1982 (SP, UEC); Serra do Caraça, ca. $10 \mathrm{~km}$ de Barão de Cocais, H.S. Irwin, R.M. Harley \& E. Onishi 28797, 22.I.1971 (US); Serra do Cipó, Retiro do Alto do Palácio, 25 km NE de Cardeal Mota, M.M. Arbo et al. 4278, 16.V.1990 (SP); Serra do Espinhaço na Lapinha, ca. $18 \mathrm{~km} \mathrm{~N}$ de Serros, H.S. Irwin et al. 20737, 23.II.1968 (UEC).

Siphanthera paludosa ocorre apenas no estado de Minas Gerais na Serra do Espinhaço, em formações de campo limpo arenoso e campo úmido. Esta espécie floresce e frutifica nos meses de janeiro-março.

Agradecimentos - À Orbélia Robinson e Frank Almeda, da California Academy of Sciences, pela leitura cuidadosa do manuscrito e divulgação de dados ainda não publicados; aos curadores dos herbários BHCB, R, RB, SP, SPF e UEC pelos empréstimos dos exemplares e à Jimi Naoki Nakajima pela arte final das figuras.

\section{Referências bibliográficas}

COGNIAUX, A. 1883-1885. Melastomataceae. In Flora Brasiliensis, volume 14 (C.F.P. de Martius, ed.). Frid. Fleischer, Munique, p.1-510.

COGNIAUX, A. 1891. Melastomataceae. In Monographiae phanerogamarum, volume 17 (A. De Candolle \& C. De Candolle, eds.). G. Masson, Paris, p.1-1256.

DE CANDOLLE, A.P. 1828. Prodomus systematis naturalis regni vegetabilis, volume 3 . Treuttel et Würtz, Paris.

HOEHNE, F.C. 1922. Melastomatáceas. Anexos das Mem. do Inst. Butantan. 1:1-198.

MIQUEL, F.A.G. 1849. Melastomaceae. Linnaea 22:537.

NAUDIN, C. 1844. Additions a la flore du Brésil Meridional. Ann. Sci. Nat. sér. III. 3:142-143.

RENNER, S.S. 1993. Phylogeny and classification of the Melastomataceae and Memecylaceae. Nord. J. Bot. 13:519-540.

WURDACK, J.J. 1958. Melastomataceae. Mem. N.Y. Bot. Gard. 10:95-117.

WURDACK, J.J. 1959. Melastomataceae. Los Angeles County Mus. Contrib. Sci. 28:8.

WURDACK, J.J. 1963. An evaluation of the genus Poteranthera. Fieldiana. 29:535-542.

WURDACK, J.J. 1973. Melastomataceae. In Flora de Venezuela volume 8 (T. Lasser, ed.). Edición Especial del Instituto Botánico, Caracas, p.1-819. 